\title{
Dynamics of freshwater snails and Schistosoma infection prevalence in schoolchildren during the construction and operation of a multipurpose dam in central Côte d'Ivoire
}

Nana R. Diakité ${ }^{*}$, Mirko S. Winkler²,3, Jean T. Coulibaly ${ }^{1,2,3,4}$, Négnorogo Guindo-Coulibaly ${ }^{1}$, Jürg Utzinger ${ }^{2,3}$ and Eliézer K. N'Goran ${ }^{1,4}$

\begin{abstract}
Background: The construction and operation of small multipurpose dams in Africa have a history of altering the transmission of water-based diseases, including schistosomiasis. The current study was designed to investigate the abundance and dynamics of schistosomiasis intermediate host snails and Schistosoma infections in humans during the construction and the first years of operation of a small multipurpose dam in Côte d'Ivoire.

Methods: The study was carried out in Raffierkro and four neighbouring villages in central Côte d'Ivoire between 2007 and 2012. Snails were collected by two experienced investigators using scoops and forceps for $15 \mathrm{~min}$ at each site. Snails were identified at genera and, whenever possible, species level, and subjected to testing for cercarial shedding. Schoolchildren aged 6-15 years were examined once every year for Schistosoma haematobium and S. mansoni infection, using urine filtration and duplication Kato-Katz thick smears, respectively. Additionally, 551 adults were examined for Schistosoma infection before (June 2007) and 359 individuals 2 years after dam construction (June 2009).

Results: Overall, 1700 snails belonging to nine different genera were collected from 19 sampling sites. Bulinus (potential intermediate host snails of S. haematobium) and Pila were the most common genera, whereas Biomphalaria (potential intermediate host snail of S. mansoni), Lymnaea, Physa and Melanoides were found in two villages. During the first-year sampling period, 65 snails were collected, of which 13 (20\%) were schistosomiasis intermediate hosts. In subsequent years, out of 1635 snails collected, 1079 (66\%) were identified as potential intermediate host for schistosomiasis, but none were shedding cercariae. The prevalence of S. mansoni among adults in the study area was low (0.4\% in 2007 and $0.3 \%$ in 2009), whereas the prevalence of S. haematobium declined from $13.9 \%$ to $2.9 \%$ in this two-year period.

(Continued on next page)
\end{abstract}

\footnotetext{
* Correspondence: diakitenanarose@yahoo.fr

${ }^{1}$ Laboratoire de Zoologie et Biologie Animale, Unité de Formation et de

Recherche Biosciences, Université Félix Houphouët-Boigny, 22 BP 522,

Abidjan 22, Côte d'Ivoire

Full list of author information is available at the end of the article
} 
(Continued from previous page)

Conclusions: The low prevalence of schistosomiasis in humans and the absence of infected intermediate host snails during the construction and early phase of operation of a small multipurpose dam suggest that there was no or only very little local transmission. However, the considerable increase in the number of intermediate host snails and their dispersion in irrigation canals call for rigorous surveillance, so that adequate public health measures can be taken in case of early signs of an outbreak.

Keywords: Schistosomiasis, Intermediate host snail, Transmission, Water resources development and management, Multipurpose dam, Côte d'Ivoire

\section{Multilingual abstracts}

Please see Additional file 1 for translations of the six official working languages of the United Nations.

\section{Background}

In many African countries large dams have been constructed for hydropower production, while small multipurpose dams aim at enhanced agricultural production and livestock breeding [1]. Environmental transformation deriving from the construction and operation of water resources are root causes for the emergence and intensification of infectious diseases transmitted by mosquito vectors (e.g. lymphatic filariasis and malaria) and snail intermediate hosts [2-7]. In Africa, snails of the genera Biomphalaria and Bulinus act as intermediate hosts for Schistosoma mansoni and S. haematobium, respectively [8,9]. Snail habitats are diverse and the transmission of schistosomiasis is governed by human-water contact patterns $[10,11]$. Hence, communities living in close proximity to infested water bodies are at risk of schistosomiasis [12].

In Côte d'Ivoire, Biomphalaria pfeifferi is the sole intermediate host of $S$. mansoni, while Bulinus truncatus and Bu. globosus are transmitting S. haematobium [13]. The construction of major water resource development projects goes back to the early 1970s. For example, two large dams were constructed on the Bandama River; i.e. Lake Kossou (completed in 1972) and Lake Taabo (filled in 1979). Both dam constructions were associated with outbreaks of S. haematobium [14]. In addition to large dams, more than 500 small multipurpose dams were built in the northern and central parts of Côte d'Ivoire [15-17]. The aim of this study was to deepen the understanding of the presence and dynamics of freshwater snail populations in the context of a hydro-agricultural development, placing particular emphasis on intermediate host snails of schistosomiasis. For this purpose, our study covered the phases of dam construction into the first years of intensified agricultural production. The investigation was carried out in the transition zone between savannah in the north and tropical rainforest in the south of Côte d'Ivoire. Our research aims at contributing to the prediction of the transmission of schistosomiasis and informing surveillance-response systems to prevent and control schistosomiasis in areas characterised by profound environmental transformation.

\section{Methods \\ Ethics statement}

This study was approved by the institutional research commission of the Centre Suisse de Recherches Scientifiques en Côte d'Ivoire (CSRS) and received approval by Bouakés health authorities. In each village, permission to work was granted by local chiefs. Community members were informed in detail about the objectives, procedures, and potential risks and benefits related to the study. Illiterate people were orally informed in the local language. Written informed consent was obtained at the beginning of the study from adult participants or from parents/guardians of children aged less than 18 years old. People found with Schistosoma infection were treated with praziquantel (40 mg/ $\mathrm{kg}$ of body weight) while a single oral dose of albendazole $(400 \mathrm{mg}$ ) was given to individuals with soil-transmitted helminth infection.

\section{Study area and population}

The study was carried out in five villages located in proximity to a small multipurpose dam (i.e. Ahougui, Koffikro, Kpokahankro, N’Douakro and Raffierkro) [18] and two villages without activities in proximity to the small dam (i.e. Mamian and N'Drikro). All villages were located near Bouaké, in the central part of Côte d'Ivoire (geographical coordinates $7^{\circ} 44^{\prime} \mathrm{N}$ latitude and $5^{\circ} 41^{\prime} \mathrm{W}$ longitude) as shown in Fig. 1.

During the study period from 2007 to 2012, the daily average temperature ranged between $23.7{ }^{\circ} \mathrm{C}$ and $33.8{ }^{\circ} \mathrm{C}$ with an average annual rainfall of $1229 \mathrm{~mm}$ and $1350 \mathrm{~mm}$. The local humid tropical climate zone is characterised by two well-defined seasons: a dry season from November to February and a long rainy season from March to October. The vegetation is typical for the transition zone from tropical rainforest to savannah. Before dam construction, people were mainly engaged in subsistence agriculture (e.g. cassava and yams). Construction of the dam provided new opportunities for local dwellers, including irrigated rice cultivation, vegetable farming and inland fish production. 


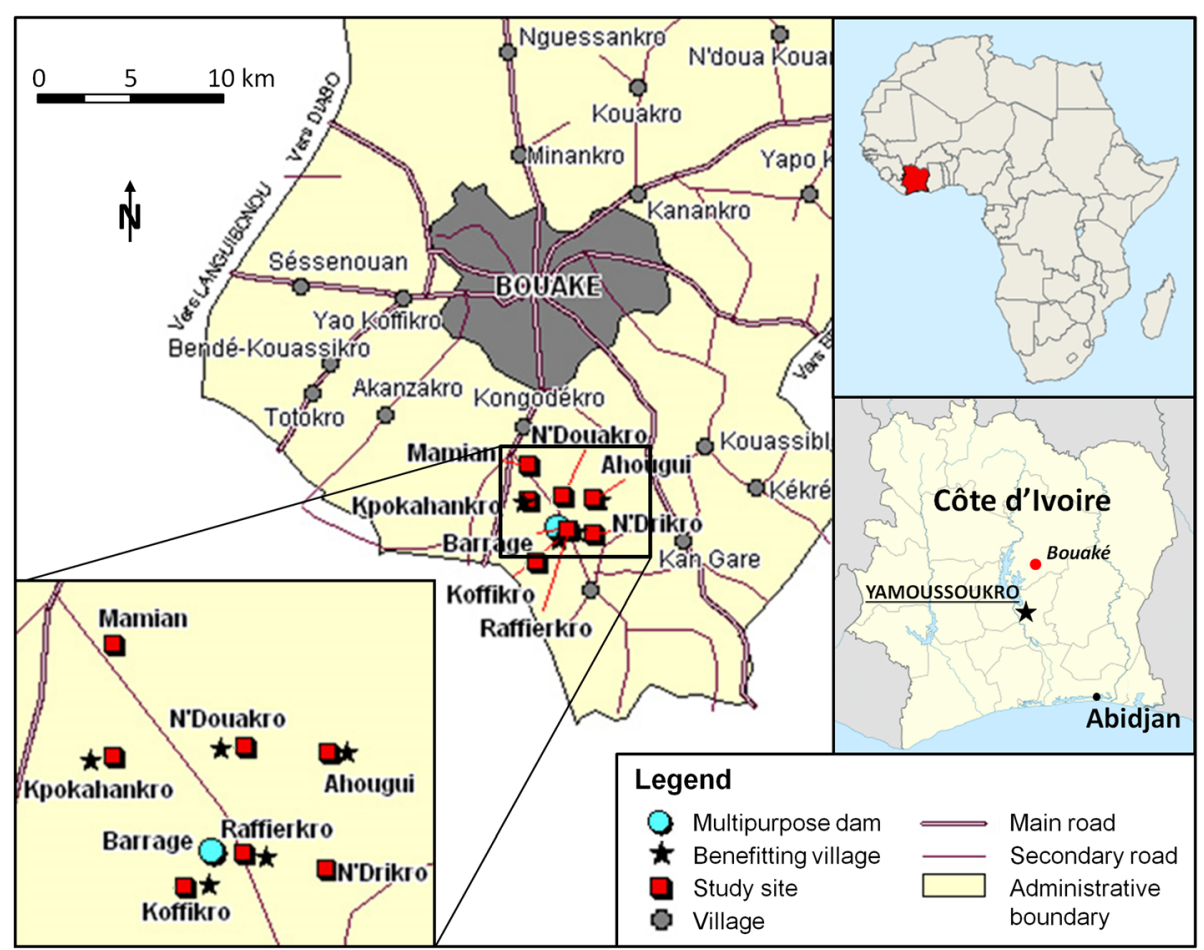

Fig. 1 Map of study site near Bouaké, central Côte d'Ivoire

\section{Study design}

This study was designed as a repeated cross-sectional survey implemented over a six-year period. During the construction of the multipurpose dam, from June 2007 to November 2009, nine malacological (M1-M9) and three parasitological (P1-P3) surveys were carried out capturing the main phases of project development (see Fig. 2): (i) the construction of the dam; (ii) the construction of the irrigation canals, agricultural fields and fish ponds; and (iii) the growing of rice-fields. In the early stages of the dam operation, the parasitological surveys were continued from 2010 to 2012 (P4-P6; in the months of June/July) for the follow up.

\section{Malacological surveys}

In each study village, all the water contact sites where people used to collect water, wash clothes, bath, swim and play (young children) were surveyed. Snail sampling was undertaken by two experienced field collectors using scoops and forceps for the duration of $15 \mathrm{~min}$. Snail habitats were characterised using a standard form. The collected snail specimens were transferred in perforated plastic boxes to a nearby laboratory. Snails were identified according to shell morphology and structure using standard identification keys $[19,20]$. After genus and/or species identification, potential intermediate host snails were tested over a one-month period for Schistosoma cercaria shedding in their swimming water after two- three hours of exposure to sunlight during five times points: the day of collection and 1, 2, 3 and 4 weeks after collection. Subsequently cercariae shedded were morphologically identified through identification keys put forward by Frandsen and Christensen [21].

\section{Parasitological survey}

A total sample size of 600 individuals was the set target for the parasitological survey, representing 50\% of the total population in the study area. For accounting for the different population numbers in the study villages, sampling proportional to size was applied. Households were randomly selected from previously prepared household list and children aged 6-15 years attending primary school were invited to participate in the survey. In addition, all primary schoolchildren from Raffierkro, N'Drikro and Mamian were screened. After informed consent, stool and urine samples were collected with the assistance of local nurses. Two plastic containers $(125 \mathrm{ml})$ were distributed to each adult participant the day before the sample collection. Participants were invited to submit a sample of their own morning stool and urine in two separate collection containers. Each participant was given a unique identification number. The samples obtained were then transferred to a nearby laboratory and worked-up the same day for S. haematobium (urine), S. mansoni and soil-transmitted helminths (stool) using standardised, quality-controlled methods. In 


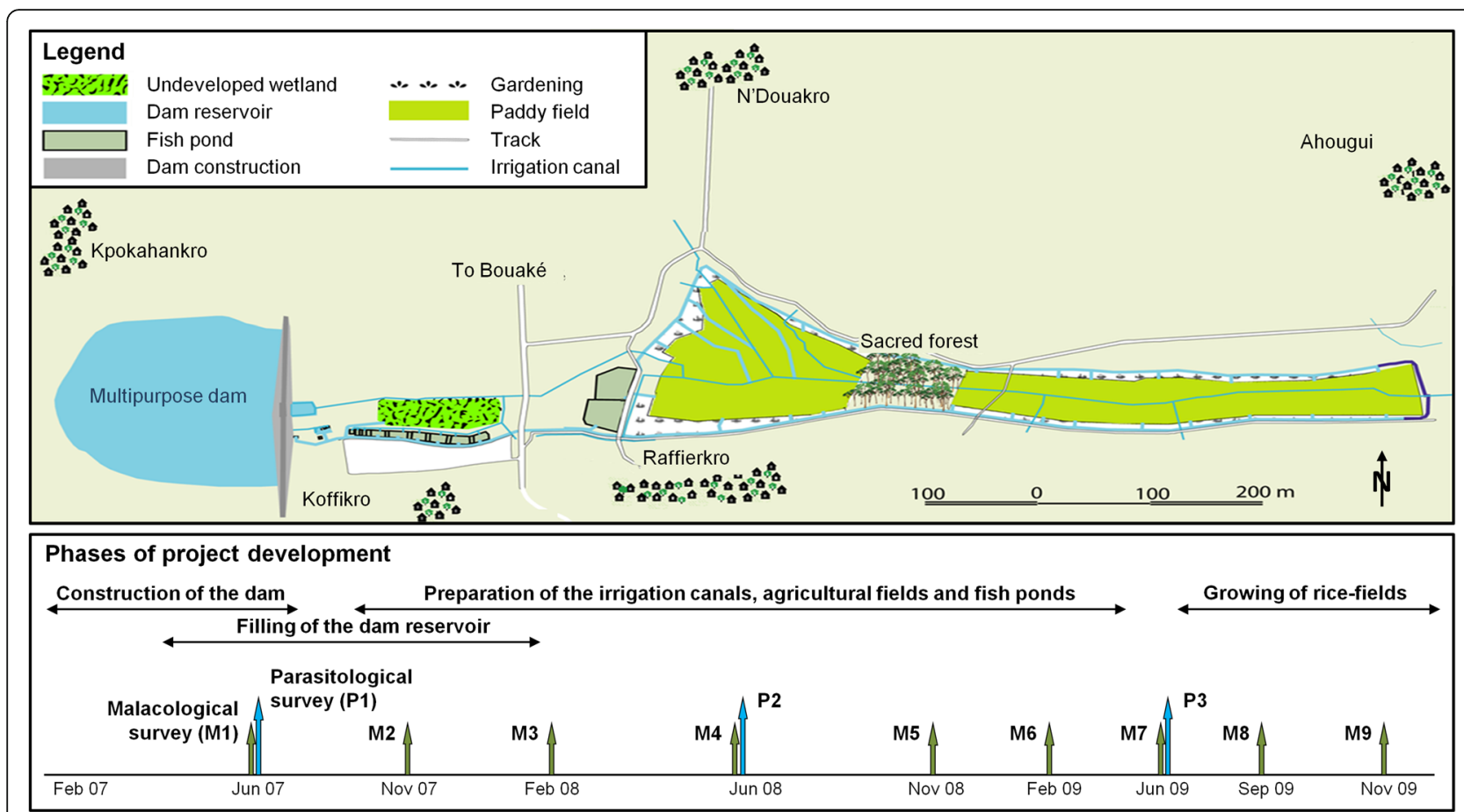

Fig. 2 Study area near Bouaké in central Côte d'Ivoire, showing the location of the study villages within the irrigation scheme, different activities around the multipurpose dam and month of malacological and parasitological surveys

brief, stool samples were processed by the Kato-Katz technique, producing two thick smears per stool per participant [22]. After a clearing time of 30-45 min, KatoKatz thick smears were examined under a microscope by experienced laboratory technicians. Helminth eggs were counted and recorded on a species-specific level. Individual egg output was expressed as eggs per gram of faeces (EPG), which was calculated as the arithmetic mean egg count from two readings multiplied by a factor of 24 . The prevalence and intensity of $S$. haematobium infection were estimated based on a urine filtration method. In brief, $10 \mathrm{ml}$ of urine was pressed through a polyamide (Nytrel) filter (mesh size: $20 \mu \mathrm{m}$ ) and stained with a drop of Lugol's solution for subsequent microscopic examination. The intensity of $S$. haematobium infection was expressed as the number of eggs per $10 \mathrm{ml}$ of urine.

\section{Statistical analysis}

Double entry of data using Excel (Microsoft; Redmond, WA, USA) was done and cross-checked with EpiInfo version 3.2 (Centers for Disease Control and Prevention; Atlanta, GA, USA). The final database was analysed using STATA version 9.0 (Stata Corporation, College Station, TX, USA). The Kruskal-Wallis (KW) test was employed to compare the differences in snail densities among villages. Pearson's $\chi^{2}$ test was used to compare proportions between villages, age categories and sex. The Student's $t$-test was used to compare means. For all statistics, a $P$ value below 0.05 was considered as statistically significant.

\section{Results}

\section{Water contact sites and snail composition}

A total of 20 human water contact sites were recorded: eight in Kpokahankro, five in Raffierkro, three in Ahougui and N'Douakro each and one in Koffikro. A total of 1700 freshwater snails were collected from the sampling sites (Table 1). Identification based on shell morphology revealed nine genera. Snails belonging to the genera Bulinus and Pila were observed in all the localities, whereas the genera Biomphalaria, Lymnaea, Physa and Melanoides were observed in only two localities (Ahougui and Raffierkro). In the early construction phase (year 2007), 65 snails belonging to three species were collected. Bi. pfeifferi in Ahougui, Bu. forskalii in Kpokahankro and Raffiekro and P. acuta in Raffiekro. During this period the intermediate host Bi. pfeifferi was observed only in Ahougui with 13 individuals.

In 2008 (advanced construction phase), 1260 snails, including the three intermediate hosts Bi. pfeifferi, $\mathrm{Bu}$. truncatus and $\mathrm{Bu}$. globosus, were collected. Most of them ( $n=1027 ; 81.5 \%$ ) were observed in Raffierkro. In the same village Bi. pfeifferi was the predominant species (64.3\%), followed by Bu. globosus (11.3\%) and Bu. truncatus (10.2\%). In 2009 (late construction phase), 
Table 1 Snail abundance in a study carried out near Bouaké in central Côte d'Ivoire between June 2007 and November 2009 , stratified by study period and village

\begin{tabular}{|c|c|c|c|c|c|c|c|c|c|c|c|c|c|}
\hline \multirow[b]{2}{*}{ Species } & \multicolumn{3}{|c|}{ Ahougui } & \multicolumn{3}{|c|}{ Kpokahankro } & \multicolumn{3}{|c|}{ N'Douakro } & \multicolumn{3}{|c|}{ Raffierkro } & \multirow[t]{2}{*}{ Total } \\
\hline & P1 & $\mathrm{P} 2$ & P3 & $\mathrm{P} 1$ & P2 & P3 & P1 & P2 & P3 & P1 & $\mathrm{P} 2$ & P3 & \\
\hline Biomphalaria pfeifferi & 13 & 0 & 0 & 0 & 0 & 0 & 0 & 0 & 0 & 0 & 660 & 52 & 725 \\
\hline Bulinus truncatus & 0 & 0 & 3 & 0 & 0 & 0 & 0 & 0 & 0 & 0 & 105 & 54 & 162 \\
\hline Bulinus globosus & 0 & 0 & 0 & 0 & 0 & 0 & 0 & 0 & 0 & 0 & 116 & 89 & 205 \\
\hline Bulinus forskalii & 0 & 11 & 21 & 12 & 55 & 50 & 0 & 0 & 5 & 15 & 35 & 10 & 214 \\
\hline Lymnaea natalensis & 0 & 0 & 3 & 0 & 0 & 0 & 0 & 0 & 0 & 0 & 7 & 5 & 15 \\
\hline Physa acuta & 0 & 0 & 3 & 0 & 0 & 0 & 0 & 0 & 0 & 25 & 30 & 3 & 61 \\
\hline Planorbe sp & 0 & 20 & 1 & 0 & 7 & 13 & 0 & 0 & 0 & 0 & 0 & 0 & 41 \\
\hline Pila africana & 0 & 10 & 24 & 0 & 9 & 6 & 0 & 0 & 1 & 0 & 51 & 0 & 101 \\
\hline Segmenorbis sp & 0 & 0 & 0 & 0 & 0 & 0 & 0 & 0 & 3 & 0 & 0 & 0 & 3 \\
\hline Melanoides tuberculata & 0 & 120 & 16 & 0 & 0 & 0 & 0 & 0 & 0 & 0 & 23 & 13 & 172 \\
\hline Lanistes sp & 0 & 1 & 0 & 0 & 0 & 0 & 0 & 0 & 0 & 0 & 0 & 0 & 1 \\
\hline Total & 13 & 162 & 71 & 12 & 71 & 69 & 0 & 0 & 9 & 40 & 1027 & 226 & 1700 \\
\hline
\end{tabular}

Koffikro: no water contacts points

the same species were observed, though with a decrease in the number of individuals for each of the three species.

Over the entire malacological study period (June 2007-November 2009), the highest number of intermediate host snails was recorded in Raffierkro. Bi. pfeifferi was the most frequently encountered intermediate host snail in Raffierkro ( $n=725 ; 42.6 \%$ ), followed by Bu. globosus $(n=205 ; 12.1 \%)$ and Bu. truncatus $(n=214 ; 12.6 \%)$. M. tuberculata was the predominant snail species in Ahougui ( $n=136 ; 55.3 \%$ ), while Bu. forskalii dominated in Kpokahankro $(n=117 ; 77.0 \%)$ and N'Douakro $(n=5 ; 55.3 \%)$. In Ahougui, few Bi. pfeifferi $(n=13)$ and $B u$. truncatus $(n=3)$ were collected during the first and the third year of the study, respectively.
Habitats and density of schistosomiasis intermediate host snails

The key habitats where snails were observed consisted of canals, the dam, paddies, swamps and water reservoirs. The mean snail abundance varied significantly across the four villages (KW $=136.5 ; P=0.025)$, with Raffierkro recording the highest abundance.

The density of schistosomiasis intermediate host snails was highest in Raffierkro. As shown in Fig. 3, during the second time-period, from June to November 2008, the number of Bi. pfeifferi increased rapidly from 0 to 449 snails. Subsequently, numbers decreased progressively from 211 to 46 and six snails from February to November 2009. With regard to $\mathrm{Bu}$. globosus, two peaks of relative

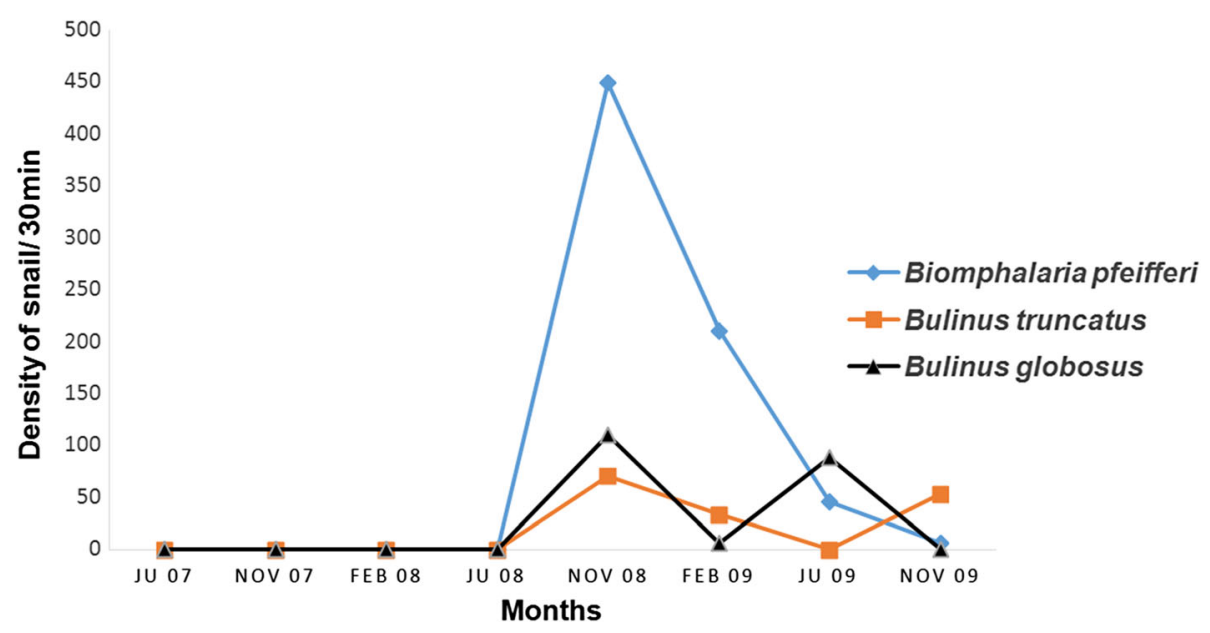

Fig. 3 Density of the three intermediates host snail species of schistosomiasis in Raffierkro from June 2007 to November 2009 
abundance were observed in November 2008 and June 2009, while Bu. truncatus showed only one peak (November 2008). No Bu. globosus snails were observed in February 2009, while Bu. truncatus population decreased. The maximum abundances of $\mathrm{Bu}$. globosus $(n=89)$ and $B u$. truncatus $(n=54)$ individuals were observed, in June and November 2009, respectively. Overall, density of snails collected in Ahougui was lower compared to Raffierkro.

\section{Infection of snails}

None of the snails was found shedding schistosome cercariae. Yet, some snails were found shedding zoophilic cercariae, such as Strigeides, and Xiphidio-cercariae.

\section{Study adherence and population characteristics}

In June 2007, stool and urine samples could be obtained from 534 and 551 people, respectively. In the last survey round conducted in June 2009, 389 and 359 stool and urine samples were obtained, respectively. The study population was mainly composed of individuals above 15 years (54.8\%). From June 2007 to June 2012, all primary schoolchildren from Raffierkro, N'Drikro and Mamian were screened.

\section{Prevalence and intensity of Schistosoma infections by sex and age}

The cumulative prevalence for the two Schistosoma species in the five study villages was significantly lower in 2009 (2.6\%, 95\% CI: $1.1-5.0 \%)$, compared to the baseline cross-sectional survey in 2007 (7.5\%, 95\% CI: 5.4$10.1 \%)$. This difference was statistically significant $\left(\chi^{2}=\right.$ 7.97; $P=0.005)$. In Table 2, the overall prevalence of Schistosoma infection in individual villages was below $6.0 \%$ at the time of the baseline assessment in 2007. Prevalences remained at similar levels during the two follow-up surveys, except for Raffierkro, where a higher prevalence was observed in $2007(P=0.005)$, associated with a difference in the prevalence between males (10.5\%) and females
(4.9\%) $\left(\chi^{2}=5.88 ; P=0.024\right)$. In the dam area, the global prevalence observed of $S$. mansoni was very low at $0.4 \%$ in 2007 and $0.3 \%$ in 2009. No infected people were observed in Ahougui, Koffikro, N’Douakro and Kpokahankro. In Raffierkro, the prevalence decreased from $1.3 \%$ to $0.7 \%$ from 2007 to 2009, respectively. All cases detected were restricted to school-aged children (6-15 years) (Table 3). The intensity of infection was very low in both 2007 and 2009 (0.01 EPG, 95\% CI: 0-0.03 EPG).

The prevalence of $S$. haematobium was also low, decreasing from $6.9 \%$ (95\% CI: 4.7-9.0\%) in 2007 to $2.2 \%$ (95\% CI: $0.7-3.8 \%)$ in $2009\left(\chi^{2}=9.86 ; P=0.002\right)$. Although the prevalence was low, a significant sex difference was observed. In 2007, males showed a significantly higher prevalence than female (9.6\% versus $4.7 \%$; $\left.X^{2}=5.20 ; P=0.022\right)$. In 2009 , the prevalence remained comparable $\left(\chi^{2}=0.38 ; P=0.54\right)$, except for Raffierkro, where a prevalence of 15.4 and $3.1 \%$ was recorded in 2007 and 2009, respectively

The geometric mean of excreted eggs/10 ml of urine was low throughout, with an observed decrease from 0.15 eggs/10 ml (95\% CI: 0.09-0.21 eggs/10 ml) in 2007 to 0.05 eggs/10 ml (95\% CI: 0.01-0.10 eggs/ml) in $2009(P=0.70)$.

Considering schoolchildren in 2007, a difference was observed in the prevalence of $S$. haematobium between Raffierkro and the two schools of Mamian and N'Drikro. The prevalence of infection in Raffierkro's school decreased from $13.9 \%$ (95\% CI: 8.3-19.4\%) to $2.9 \%$ (95\% CI: 0.4-6.2\%) in 2009. During the 2010 and 2011 cross-sectional surveys, no Schistosoma infection was observed in the three schools. In 2012, only one and four cases were observed in Raffierkro and N'Drikro, respectively (Table 4). All of these cases were detected in children aged between six and ten years.

\section{Discussion}

\section{Abundance of snails}

The current study aimed to deepen our understanding of the variation of freshwater snail populations in central

Table 2 Prevalence of S. haematobium and S. mansoni in the study villages near Bouaké in central Côte d'Ivoire in proximity to dam between June 2007 and November 2009

\begin{tabular}{|c|c|c|c|c|c|c|c|c|}
\hline \multirow[b]{3}{*}{ Village } & \multicolumn{4}{|l|}{2007} & \multicolumn{4}{|c|}{2009} \\
\hline & \multicolumn{2}{|c|}{ S. haematobium } & \multicolumn{2}{|c|}{ S. mansoni } & \multicolumn{2}{|c|}{ S. haematobium } & \multicolumn{2}{|c|}{ S. mansoni } \\
\hline & $n$ & $p(\%)$ & $n$ & $p(\%)$ & $n$ & $\mathrm{p}(\%)$ & $n$ & $\mathrm{p}(\%)$ \\
\hline Ahougui & 101 & $3(2.9)$ & 99 & 0 & 83 & $1(1.2)$ & 85 & 0 \\
\hline Koffikro & 91 & $3(3.3)$ & 90 & 0 & 45 & $2(4.4)$ & 51 & 0 \\
\hline Kpokahankro & 110 & $4(3.6)$ & 109 & 0 & 65 & $1(1.5)$ & 73 & 0 \\
\hline N'Douakro & 87 & $3(3.5)$ & 79 & 0 & 35 & 0 & 38 & 0 \\
\hline Raffierkro & 162 & $25(15.4)$ & 157 & $2(1.3)$ & 131 & $4(3.1)$ & 142 & $1(0.7)$ \\
\hline Total & 551 & $38(6.9)$ & 534 & $2(0.4)$ & 359 & $8(2.2)$ & 389 & $1(0.3)$ \\
\hline
\end{tabular}

$n$ : number of individuals examined

$\mathrm{p}$ : number of individuals infected

$\%$ : prevalence 
Table 3 Prevalence of S. haematobium in the five study villages near Bouaké in central Côte d'Ivoire, stratified by age category between 2007 and 2009

\begin{tabular}{|c|c|c|c|c|c|c|}
\hline \multirow[b]{2}{*}{ Age category (in years) } & \multicolumn{2}{|c|}{2007} & \multicolumn{2}{|c|}{2009} & \multirow[b]{2}{*}{$x^{2}$} & \multirow[b]{2}{*}{$P$-value } \\
\hline & $n$ & $p(\%)$ & $n$ & $p(\%)$ & & \\
\hline$\leq 5$ & 38 & $3(7.9)$ & 36 & $1(2.7)$ & & \\
\hline $6-15$ & 198 & $23(11.6)$ & 140 & $4(3.0)$ & & \\
\hline$>15$ & 315 & $12(3.8)$ & 183 & $3(1.6)$ & & \\
\hline Total & 551 & $38(6.9)$ & 372 & $8(2.2)$ & 7.40 & 0.006 \\
\hline
\end{tabular}

$n$ : number of individuals examined

p: number of individuals infected

$\%$ : prevalence

Côte d'Ivoire in the face of the construction and operation of a small, multipurpose dam. We observed a considerable increase in the abundance of snails during the second observation period, i.e. after the dam had been filled. The diversity of freshwater snails and the exponential growth of Bi. pfeifferi are probably explained by a more stable hydrological system [23]. All the snails collected belonged to the same genera and species that have been reported before in the greater Bouaké area [24] with the exception of Physa acuta that had not been reported before. Bu. truncatus was present at the level of the dam reservoir but absent in the other villages having water supply points and being drained completely during the dry season. Bu. truncatus is a cosmopolitan species with a preference for sunlight, clean, stagnant and permanent aquatic environments [19]. The construction of a multipurpose dam and formation of a small man-made lake support the proliferation of $\mathrm{Bu}$. truncatus. In a preceding study by Poda in Burkina Faso it was noted that dams account for $61.7 \%$ of the biotopes with $\mathrm{Bu}$. truncatus and seem the preferential habitats of this species [8]. This observation is similar to that described in our context. In contrast, $\mathrm{Bu}$. globosus prefers cluttered areas and low water flow such as in an irrigated area $[25,26]$.

\section{Cercarial shedding and schistosomiasis transmission}

In spite of very high abundance of snails and prolonged exposure (up to 1 month) to check for cercarial shedding, none of the snails collected shed cercariae and the schistosome infection level among school children and adults was low. Indeed, with a Schistosoma infection prevalence below 10\%, all the localities surveyed are considered hypoendemic [27]. This observation suggests that the high abundance of intermediate host snails does not correlate with human infection. These results are consistent with other studies from endemic areas in Uganda and Kenya; showing a high abundance of snails but no or only very few snails shedding cercariae [28, 29]. Indeed, the quasi-absence of cercariae shedding might explain the low human prevalence. The absence of infection might be due to health education received by parents
Table 4 Prevalence of schistosomiasis in children 6-15 years in the five study villages near Bouaké in central Côte d'Ivoire from 2007 to 2012

\begin{tabular}{|c|c|c|c|c|c|c|c|}
\hline \multirow[b]{3}{*}{ School } & \multirow[b]{3}{*}{$n$} & \multirow[b]{3}{*}{$p(\%)$} & \multicolumn{5}{|c|}{ Sex } \\
\hline & & & \multicolumn{2}{|c|}{ Female } & \multicolumn{2}{|c|}{ Male } & \multirow[b]{2}{*}{$P$-value } \\
\hline & & & $\bar{n}$ & $p(\%)$ & $\bar{n}$ & $p(\%)$ & \\
\hline \multicolumn{8}{|c|}{2007 (P1: 24-30 June) } \\
\hline Raffierkro & 151 & $21(13.9)$ & 56 & $7(12.5)$ & 95 & $14(14.7)$ & 0.701 \\
\hline Mamian & 22 & 0 & 0 & 0 & 0 & 0 & - \\
\hline N'Drikro & 28 & 0 & 0 & 0 & 0 & 0 & - \\
\hline \multicolumn{8}{|c|}{2008 (P2: 28 May-3 June) } \\
\hline Raffierkro & 184 & $8(4.3)$ & 81 & $2(2.4)$ & 103 & $6(5.8)$ & 0.268 \\
\hline Mamian & 77 & $1(1.3)$ & 28 & 0 & 49 & 2 & 0.447 \\
\hline N'Drikro & 100 & $4(4.0)$ & 50 & 6 & 50 & 2 & 0.327 \\
\hline \multicolumn{8}{|c|}{2009 (P3: 21-25 June) } \\
\hline Raffierkro & 138 & $4(2.9)$ & 61 & $2(3.3)$ & 77 & $2(3.8)$ & 0.852 \\
\hline Mamian & 113 & 0 & 0 & 0 & 0 & 0 & - \\
\hline N'Drikro & 115 & $2(1.8)$ & 61 & 1 (1.6) & 54 & $1(1.9)$ & 0.932 \\
\hline \multicolumn{8}{|c|}{2010 (P4: 27 May-1 June) } \\
\hline Raffierkro & 154 & 0 & 60 & 0 & 94 & 0 & - \\
\hline Mamian & 103 & 0 & 43 & 0 & 60 & 0 & - \\
\hline N'Drikro & 164 & 0 & 70 & 0 & 94 & 0 & - \\
\hline \multicolumn{8}{|c|}{2011 (P5: 10-15 July) } \\
\hline Raffierkro & 239 & 0 & 96 & 0 & 143 & 0 & - \\
\hline Mamian & 94 & 0 & 40 & 0 & 54 & 0 & - \\
\hline N'Drikro & 159 & 0 & 74 & 0 & 85 & 0 & - \\
\hline \multicolumn{8}{|c|}{2012 (P6: 30 May-3 June) } \\
\hline Raffierkro & 155 & $3(1.9)$ & 60 & $1(1.6)$ & 95 & $2(2.1)$ & \\
\hline Mamian & 72 & 0 & 28 & 0 & 43 & 0 & \\
\hline N'Drikro & 86 & $5(5.8)$ & 44 & 9.09 & 42 & 2.38 & \\
\hline
\end{tabular}

$n$ : number of individuals examined

$\mathrm{p}$ : number of individuals infected

$\%$ : prevalence

and children, who emphasised avoidance of water contact such as bathing, washing clothes or kitchen utensils in the newly formed water resource. The surveys undertaken confirmed the low prevalence observed. Hence, it is conceivable that there was no local transmission of schistosomiasis at the time of the study despite suitable snail habitats. The few infected people might have acquired their infections elsewhere.

S. mansoni was rarely found in the study area. This result is consistent with observations made before in villages in close proximity to large dams, namely Lake Kossou and Lake Taabo. However, within a few years of construction of these two large dams, there were outbreaks of $S$. haematobium, prevalence increased from $14 \%$ to $53 \%$ and from $0 \%$ to $73 \%$ in the two dams, while $S$. mansoni was absent or present at very low rate [14]. 
Our study confirms that Central region of Côte d'Ivoire continues to have active transmission of $S$. haematobium. The fall of the prevalence of schistosomiasis in all the study localities might be associated with the absence of indigenous transmission and the treatment of diagnosed cases. Of note, all positive individuals were treated with praziquantel $(40 \mathrm{mg} / \mathrm{kg})$, which, according to $\mathrm{WHO}$, results in cure rates ranging between $60 \%$ and $90 \%$ for Schistosoma infection [30, 31].

Our study illustrates the complex interactions between dam constructions, snail ecology and schistosomiasis transmission. Therefore, before any dam construction and throughout the life course of such water resources development projects, malacological and epidemiological survey must be implemented to continuously evaluate potential risks. Integrated control measures, including information, education and communication (IEC), environment management and access to treatment must be considered. Control and preventive measures that are readily tailored to specific settings are necessary to keep human infections and morbidity low.

\section{Conclusions}

The construction and operation of a small, multipurpose dam in Raffierkro in central Côte d'Ivoire is the likely cause of a high increase of intermediate host snail fauna. Bi. pfeifferi was the prominent intermediate host of schistosomiasis, followed by $\mathrm{Bu}$. truncatus and Bu. globosus. In spite of the presence of dam and the high abundance of intermediate host snails, no evidence of local transmission of schistosomiasis was observed. Hence, adequate control and preventive measures in this context by IEC, and rigorous surveillance is necessary, so that early signs of emergences can be addressed by public health measures.

\section{Additional file}

Additional file 1: Multilingual abstracts in the six official working

languages of the United Nations. (PDF $786 \mathrm{~kb}$ )

\begin{abstract}
Abbreviations
Cl: Confidence interval; CSRS: Centre Suisse de Recherches Scientifiques en Côte d'Ivoire; DBL: Danish Bilharziasis Laboratory; FAO: Food and Agriculture Organization; KW: Kruskal-Wallis; WHO: World Health Organization
\end{abstract}

\section{Acknowledgements}

We thank Dr. Gilbert Raffier, the collector's team and all the population of the seven villages. We are grateful to colleagues from FAIRMED. Thanks are addressed to Diabaté Salia and Kouassi Laurent for their technical assistance during the snail collection and laboratory analysis. We are also grateful to Coulibaly Bamoro for generating the map of the study site.

\section{Funding}

This study was financially supported by the Swiss-based non-governmental organization FAIRMED (Bern, Switzerland).

\section{Authors' contribution}

NRD, JU and EKN designed the study; NRD and EKN implemented the study; NRD, NGC and EKN collected the data; NRD and JTC managed the data; NRD, MSW, JU and EKN analysed and interpreted the data; NRD wrote the first draft of the paper. All authors revised and approved the final manuscript before submission.

\section{Competing interests}

The authors declare that they have no competing interests.

\section{Consent for publication}

Not applicable.

\section{Ethics approval and consent to participate}

This study was approved by the institutional research commission of the Centre Suisse de Recherches Scientifiques en Côte d'Ivoire (CSRS) in Abidjan, Côte d'Ivoire and received approval by Bouaké's health authorities. In each village, permission to work was granted by local chiefs. Community members were informed in detail about objectives, procedures, and potential risks and benefits related to the study. Illiterate people were orally informed in the local language. Written informed consent was obtained at the beginning of the study from adult participants or from parents/ guardians of children (less than 18 years old)

\section{Author details}

${ }^{1}$ Laboratoire de Zoologie et Biologie Animale, Unité de Formation et de Recherche Biosciences, Université Félix Houphouët-Boigny, 22 BP 522, Abidjan 22, Côte d'Ivoire. ${ }^{2}$ Swiss Tropical and Public Health Institute, P.O. Box CH-4002, Basel, Switzerland. ${ }^{3}$ University of Basel, P.O. Box, CH-4003, Basel, Switzerland. ${ }^{4}$ Département Environnement et Santé, Centre Suisse de Recherches Scientifiques en Côte d'Ivoire, 01 BP 1303, Abidjan 01, Côte d'Ivoire.

Received: 14 September 2016 Accepted: 17 April 2017

Published online: 04 May 2017

\section{References}

1. FAO. Dams and agriculture in Africa. Dams Africa: Food and Agriculture; Organization; 2007

2. Know W. Mosquito production and species succession from an area of irrigated rice fields in The Gambia, West Africa. J Trop Med Hyg. 1983;86:237-45

3. Hunter JM, Rey L, Chu KY, Adekolu-John EO, Mott KE. Parasitic diseases in water resources development. The need for intersectoral negotiation. Geneva: World Health Organization; 1993.

4. Patz JA, Graczyk TK, Geller N, Vittor AY. Effects of environmental change on emerging parasitic diseases. Int J Parasitol. 2000:30:1395-405.

5. Steinmann P, Keiser J, Bos R, Tanner M, Utzinger J. Schistosomiasis and water resources development: systematic review, meta-analysis, and estimates of people at risk. Lancet Infect Dis. 2006;6:411-25.

6. WHO. Schistosomiasis: number of people receiving preventive chemotherapy in 2012. Wkly Epidemiol Rec. 2014;89:21-8.

7. Kibret S, Lautze J, McCartney M, Nhamo L, Wilson GG. Malaria and large dams in sub-Saharan Africa: future impacts in a changing climate. Malar J. 2016;15:448

8. Poda JN, Wango SP, Sorgho H, Dianou D. Évolution récente des schistosomoses dans le complexe hydro-agricole du Sourou au Burkina Faso. Bull Soc Path Exot. 2004:97:15-8.

9. Poda JN, Mwanga J, Dianou D, Garba M, Ouédraogo FC, Zongo D, et al. Les parasitoses qui minent les nouveaux pôles de développement au Burkina Faso: cas des schistosomoses et des géohelminthes dans le complexe hydro-agricole du Sourou. VertigO. 2006;2:1-7.

10. Huang $Y X$, Manderson $L$. The social and economic context and determinants of schistosomiasis japonica. Acta Trop. 2005;96:223-31.

11. Aagaard-Hansen J, Mwanga JR, Bruun B. Social science perspectives on schistosomiasis control in Africa: past trends and future directions. Parasitology. 2009:136:1747-58

12. Utzinger J, N'Goran EK, Caffrey CR, Keiser J. From innovation to application: social-ecological context, diagnostics, drugs and integrated control of schistosomiasis. Acta Trop. 2011;120 Sppl 1:S121-37. 
13. N'Goran EK, Yapi YG, Bellec C, Sellin B. Données préliminaires sur les variations journalières des densités cercariennes de Schistosoma mansoni dans deux foyers forestiers de schistosomose intestinale dans la région de Man (Côte d'Ivoire). Bull Med Trad Phar. 1989;3:117-27.

14. N'Goran EK, Diabate S, Utzinger J, Sellin B. Changes in human schistosomiasis levels after the construction of two large hydroelectric dams in central Côte d'Ivoire. Bull World Health Organ. 1997;75:541-5.

15. Anonymous. Inventaire des retenues et barrages de Côte d'Ivoire, Direction des Grands Travaux, Abidjan; 1992, 151 p.

16. Aka M, Pagano M, Saint-Jean L, Arfi R, Bouvy M, Cecchi P, et al. Zooplankton variability in 49 shallow tropical reservoirs of Ivory Coast (West Africa). Int Rev Hydrobiol. 2000;85:491-504.

17. Yapi YG, Briet OJT, Diabate S, Vounatsou P, Akodo E, Tanner M, Teuscher T. Rice irrigation and schistosomiasis in savannah and forest areas of Côte d'Ivoire. Acta Trop. 2005:93:201-11.

18. Diakité NR, Guindo-Coulibaly N, Adja AM, Ouattara M, Coulibaly JT, Utzinger $J$, et al. Spatial and temporal variation of malaria entomological parameters at the onset of a hydro-agricultural development in central Côte d'Ivoire. Malar J. 2015;14:340

19. Brown DS. Freshwater snails of Africa and their medical importance. $2^{\text {nd }}$ ed. London: Taylor and Francis; 1994.

20. WHO. A field guide to African freshwater snails, Danish Bilharziasis Laboratory. Charlottenlund, Denmark: WHO Collaborating Centre for Applied Malacology; 1998.

21. Frandsen F, Christensen NO. An introductory guide to the identification of cercariae from African freshwater snail with special reference to cercariae of species of medical and veterinary importance. Acta Trop. 1984;41:181-202.

22. Katz N, Chaves A, Pellegrino J. A simple device for quantitative stool thicksmear technique in schistosomiasis mansoni. Rev Inst Med Trop Sao Paulo. 1972;14:397-400.

23. Utzinger J, Tanner M. Microhabitat preferences of Biomphalaria pfeifferi and Lymnaea natalensis in a natural and a man-made habitat in south eastern Tanzania. Mem Inst Oswaldo Cruz. 2000:95:287-94.

24. Demba B. Etude comparée de deux foyers de bilharziose urinaire à Schistosoma haematobium transmises par Bulinus globosus (Morelet, 1866) et Bulinus truncatus rohlfsi (Clessin, 1886). Mémoire de DEA Entomologie Médicale, Université Nationale, Côte d'Ivoire. 1989; n²9: 67 p.

25. Betterton C, Ndifon GT, Bassey SE, Tan RM, Oyeyi T. Schistosomiasis in Kano State, Nigeria. I. Human infections near dam sites and the distribution and habitat preferences of potential snail intermediate hosts. Ann Trop Med Parasitol. 1988;82:561-70.

26. Cecchi P, Baldé S, Yapi YG. Mollusques hôtes intermédiaires de bilharzioses dans les petits barrages. In: L'eau en partage. Les petits barrages de Côte d'Ivoire, ed. Cecchi, P. Latitudes 23. Paris: IRD Editions. 2007:175-189.

27. Montresor A, Crompton DWT, Gyorkos TW, Saviolo L. Helminth control in school-age children: a guide for manager of control programs. Geneva: World Health Organization; 2002. p. 64.

28. Standley CJ, Adriko M, Arinaitwe M, Atuhaire A, Kazibwe F, Fenwick A, et al. Epidemiology and control of intestinal schistosomiasis on the Sesse Islands, Uganda: integrating malacology and parasitology to tailor local treatment recommendations. Parasit Vectors. 2010;3:64.

29. Opisa S, Odiere MR, Jura WG, Karanja DM, Mwinzi PN. Malacological survey and geographical distribution of vector snails for schistosomiasis within informal settlements of Kisumu City, western Kenya. Parasit Vectors. 2011;4:226

30. Landouré $A$, Dembélé $R$, Goita $S$, Kané $M$, Tuinsma $M$, Sacko $M$, et al. Significantly reduced intensity of infection but persistent prevalence of schistosomiasis in a highly endemic region in Mali after repeated treatment. PLoS Negl Trop Dis. 2012;6:e1774

31. Garba A, Lamine MS, Barkiré N, Djibo A, Sofo B, et al. Efficacy and safety of two closely spaced doses of praziquantel against Schistosoma haematobium and S. mansoni and re-infection patterns in school-aged children in Niger. Acta Trop. 2013;128:334-44.

\section{Submit your next manuscript to BioMed Central and we will help you at every step:}

- We accept pre-submission inquiries

- Our selector tool helps you to find the most relevant journal

- We provide round the clock customer support

- Convenient online submission

- Thorough peer review

- Inclusion in PubMed and all major indexing services

- Maximum visibility for your research

Submit your manuscript at www.biomedcentral.com/submit

CBiomed Central 